November 25, 2008

DOE Grant DEFG02-00ER15028

Final Report for 2006-2007 funding period

Computational and Spectroscopic Investigations

of The Molecular Scale Structure and Dynamics

of Geologically Important Fluids and Mineral-Fluid Interfaces

Principal Investigator

R. James Kirkpatrick

Department of Geology

University of Illinois

Urbana, IL 61801

Present address:

College of Natural Science

Michigan State University

East Lansing, MI 48824
Senior Research Scientist

Andrey G. Kalinichev

Department of Geology

University of Illinois

Urbana, IL 61801

Present address:

Department of Chemistry

Michigan State University

East Lansing, MI 48824 


\section{Introduction and Summary.}

This is the final report for the calendar 2006 and 2007 years of funding for grant DOE DEFG02-00ER15028, "Computational and Spectroscopic Investigations of the Molecular Scale Structure and Dynamics of Geologically Important Fluids and Mineral-Fluid Interfaces": R. James Kirkpatrick, PI, Andrey G. Kalinichev, Senior Research Scientist. This grant was originally awarded at the University of Illinois at Urbana-Champaign, but the principal investigator and senior research scientist have moved to Michigan State University at the end of 2007, and in 2008 the funding is renewed there under the same title, but with a different grant number.

Research supported by this grant focuses on molecular scale understanding of central issues related to the structure and dynamics of geochemically important fluids, fluid-mineral interfaces, and confined fluids using computational modeling and experimental methods. Molecular scale knowledge about fluid structure and dynamics, how these are affected by mineral surfaces and molecular-scale (nano-) confinement, and how water molecules and dissolved species interact with surfaces is essential to understanding the fundamental chemistry of a wide range of low-temperature geochemical processes, including sorption and geochemical transport. Our principal efforts are devoted to continued development of relevant computational approaches, application of these approaches to important geochemical questions, relevant NMR and other experimental studies, and application of computational modeling methods to understanding the experimental results. The combination of computational modeling and experimental approaches is proving highly effective in addressing otherwise intractable problems.

In 2006-2007 we have significantly advanced in new, highly promising research directions along with completion of on-going projects and final publication of work completed in previous years. New computational directions are focusing on modeling proton exchange reactions in aqueous solutions using $a b$ initio molecular dynamics (AIMD), metadynamics (MTD), and empirical valence bond (EVB) approaches. Proton exchange is critical to understanding the structure, dynamics, and reactivity at mineral-water interfaces and for oxyions in solution, but has traditionally been difficult to model with molecular dynamics (MD). Our ultimate objective is to develop this capability, because MD is much less computationally demanding than quantum-chemical approaches. We have also extended our previous MD simulations of metal binding to natural organic matter (NOM) to a much longer time scale (up to $10 \mathrm{~ns}$ ) for significantly larger systems. These calculations have allowed us, for the first time, to study the effects of metal cations with different charges and charge density on the NOM aggregation in aqueous solutions. Other computational work has looked at the longer-time-scale dynamical behavior of aqueous species at mineral-water interfaces investigated simultaneously by NMR spectroscopy.

Our experimental NMR studies have focused on understanding the structure and dynamics of water and dissolved species at mineral-water interfaces and in two-dimensional nano-confinement within clay interlayers. Combined NMR and MD study of $\mathrm{H}_{2} \mathrm{O}, \mathrm{Na}^{+}$, and $\mathrm{Cl}^{-}$ interactions with the surface of quartz has direct implications regarding interpretation of sum frequency vibrational spectroscopic experiments for this phase and will be an important reference for future studies. We also used NMR to examine the behavior of $\mathrm{K}^{+}$and $\mathrm{H}_{2} \mathrm{O}$ in the interlayer and at the surfaces of the clay minerals hectorite and illite-rich illite-smectite. This the first time $\mathrm{K}^{+}$dynamics has been characterized spectroscopically in geochemical systems. 
Preliminary experiments were also performed to evaluate the potential of ${ }^{75}$ As NMR as a probe of arsenic geochemical behavior. The ${ }^{75}$ As NMR study used advanced signal enhancement methods, introduced a new data acquisition approach to minimize the time investment in ultrawide-line NMR experiments, and provides the first evidence of a strong relationship between the chemical shift and structural parameters for this experimentally challenging nucleus.

We have also initiated a series of inelastic and quasi-elastic neutron scattering measurements of water dynamics in the interlayers of clays and layered double hydroxides. The objective of these experiments is to probe the correlations of water molecular motions in confined spaces over the scale of times and distances most directly comparable to our MD simulations and on a time scale different than that probed by NMR. This work is being done in collaboration with Drs. C.-K. Loong, N. de Souza, and A.I. Kolesnikov at the Intense Pulsed Neutron Source facility of the Argonne National Lab, and Dr. A. Faraone at the NIST Center for Neutron Research. A manuscript reporting the first results of these experiments, which are highly complimentary to our previous NMR, X-ray, and infra-red results for these phases, is currently in preparation.

In total, in 2006-2007 our work has resulted in the publication of 14 peer-reviewed research papers (Table 1). We also devoted considerable effort to making our work known to a wide range of researchers, as indicated by the 24 contributed abstracts and 14 invited presentations listed in Table 2.

Table 1. Research papers supported by the grant and published in 2006-2007.

1. Wang, J., Kalinichev, A.G., and Kirkpatrick, R.J. (2006) Effects of substrate structure and composition on the structure, dynamics and energetics of water on mineral surfaces: a molecular dynamics modeling study, Geochim. Cosmochim. Acta, 70, 562-582.

2. Kumar P, P., Kalinichev. A.G., and Kirkpatrick, R. J. (2006) Hydration, swelling, interlayer structure, and hydrogen bonding in organo-layered double hydroxides: Insights from molecular dynamics simulation of citrate-intercalated hydrotalcite, J. Phys. Chem. B. 110, 3841-3844.

3. Kim, Y., and Kirkpatrick, R. J. (2006) ${ }^{11}$ B NMR investigation of boron interaction with mineral surfaces: results for boehmite, silica gel and illite, Geochim. Cosmochim. Acta, 70, 3231-3238.

4. Reinholdt, M. X., and R. J. Kirkpatrick (2006) Experimental investigations of amino acid-layered double hydroxide complexes: Glutamate-hydrotalcite, Chemistry of Materials, 18, 2567-2576.

5. Xu, X., Kalinichev, A. G., and Kirkpatrick, R. J. (2006) ${ }^{133} \mathrm{Cs}$ and ${ }^{35} \mathrm{Cl}$ NMR spectroscopy and molecular dynamics modeling of $\mathrm{Cs}^{+}$and $\mathrm{Cl}^{-}$complexation with natural organic matter, Cosmochim. Geochim. Acta, 70, 4319-4331.

6. Bondarenko, G. V., Gorbaty, Yu. E., Okhulkov, A. V. and Kalinichev, A. G. (2006) Structure and hydrogen bonding in liquid and supercritical aqueous $\mathrm{NaCl}$ solutions at a pressure of 1,000 bar and temperatures up to $500^{\circ} \mathrm{C}$ : A comprehensive experimental and computational study. J. Phys. Chem. A, 110, 4042-4052

7. Q.Li, R.J.Kirkpatrick (2007) Organic anions in layered double hydroxides: An experimental investigation of citrate hydrotalcite Amer. Mineralogist, 92, 397-402.

8. P.Kumar, A.G.Kalinichev, R.J.Kirkpatrick (2007a) Dissociation of carbonic acid: Gas phase energetics and mechanism from ab initio metadynamics simulations. J.Chem.Phys., 126, 204315-1-7.

9. A.G.Kalinichev, R.J.Kirkpatrick (2007) Molecular dynamics simulation of cationic complexation with natural organic matter. European Journal of Soil Science, 58, 909-917.

10. I.S.Ufimtsev, A.G.Kalinichev, T.J.Martinez, R.J.Kirkpatrick (2007) A charged ring model for classical OH-(aq) simulations. Chem.Phys.Lett., 442, 128-133.

11. P.Kumar, A.G.Kalinichev, R.J.Kirkpatrick (2007b) Molecular dynamics simulation of the energetics and 
structure of layered double hydroxides intercalated with carboxylic acids. J.Phys.Chem.C, 111, 13517 - 13523.

12 A.G.Kalinichev, J.Wang, R.J.Kirkpatrick (2007) Molecular dynamics modeling of the structure, dynamics and energetics of mineral-water interfaces: application to cement materials. Cement and Concrete Research, 37, 337-347.

13. J.-P.Korb, P.J.McDonald, L.Monteilhet, A.G.Kalinichev, R.J.Kirkpatrick (2007) Comparison of proton fieldcycling relaxometry and molecular dynamics simulations for proton-water surface dynamics in cement-based materials. Cement and Concrete Research, 37, 348-350.

14. G.M.Bowers, R.J.Kirkpatrick. (2007) High-field NMR study of arsenic oxysalts. Journal of Magnetic Resonance. 188, 311-321.

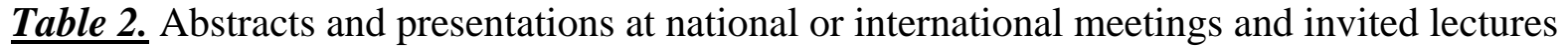
during the past year.

\section{Presentations at national and international meetings}

1. Kirkpatrick, R.J., Kumar, P., Kalinichev, A.G., Reinholdt, M.X., and Li, Q., Energetics and structure of organic- and bio-molecules at solid surfaces: an experimental and molecular modeling study of carboxylic species on layered double hydroxides, Materials Research Society 2006 Spring Meeting, Abstr. JJ.1.3, San Francisco, April 2006.

2. Kalinichev, A.G., Wang, J., and Kirkpatrick, R.J., Molecular ordering, structure, and dynamics of water at mineral surfaces: MD computer simulation, Materials Research Society 2006 Spring Meeting, Abstr. JJ.5.3, San Francisco, April 2006.

3. Kalinichev, A.G., Wang, J., and Kirkpatrick, R.J., Molecular dynamics simulation of water at mineral surfaces: Structure, dynamics, energetics and hydrogen bonding, AGU 2006 Spring Meeting, Abstr. V22A-04, Baltimore, MD, May 2006.

4. Kirkpatrick, R.J., Kalinichev, A.G., Wang, J., Reinholdt, M.X., Kumar, P., Li, Q., and Xu, X. Molecular modeling and experimental NMR studies of interfacial and confined geochemical fluids, 2006 Gordon Research Conference "Water \& Aqueous Solutions”, Plymouth, NH, July 2006.

5. Kalinichev, A.G., Wang, J., and Kirkpatrick, R.J., Molecular dynamics simulation of the structure, dynamics, and energetics of water at mineral surfaces, 16th Symposium on Thermophysical Properties, Boulder, CO, July 2006.

6. Kirkpatrick, R.J., Kalinichev, A.G., Kumar, P., Reinholdt, M.X., and Li, Q., NMR and molecular modeling studies of geochemical aqueous interfaces, American Chemical Society 232nd National Meeting, Abstr. 469COLL, San Francisco, Sept. 2006.

7. Kalinichev, A.G., Wang, J., and Kirkpatrick, R.J., Molecular dynamics of mineral-water interfaces: Structure, dynamics, energetics and hydrogen bonding, American Chemical Society 232nd National Meeting, Abstr. 472COLL, San Francisco, Sept. 2006.

8. Reinholdt, M.X , Babu, P.K., and Kirkpatrick, R.J., Glutamate intercalation/adsorption on layer double hydroxide: a 13C MAS and 1H T1 relaxation investigation of the organic-inorganic interface, American Chemical Society 232nd National Meeting, Abstr. 421-COLL, San Francisco, Sept. 2006.

9. Kalinichev, A.G., Bondarenko, G.V., Gorbaty, Yu.E., and Kirkpatrick, R.J., Structure and hydrogen bonding in hydrothermal $\mathrm{H} 2 \mathrm{O}-\mathrm{NaCl}$ solutions: are IR and Raman vibrational spectra telling us the whole story? American Chemical Society 232nd National Meeting, Abstr. 007-GEOC, San Francisco, Sept. 2006.

10. Kalinichev, A.G., and Kirkpatrick, R.J., Molecular dynamics simulation of cationic complexation with natural organic matter, American Chemical Society 232nd National Meeting, Abstr. 011-GEOC, San Francisco, Sept. 2006.

11. Kumar, P., Kalinichev, A.G., and Kirkpatrick, R.J., Ab initio molecular dynamics study of carbonic acid in aqueous environment. American Chemical Society 232nd National Meeting, Abstr. 043-COMP, San Francisco, Sept. 2006.

12. Ufimtsev, I.S., Kalinichev, A.G., Martinez, T.J., and Kirkpatrick, R.J., Multi-state empirical valence bond MD simulation of hydroxyl ion transfer in liquid water, American Chemical Society 232nd National Meeting, Abstr. 077-COMP, San Francisco, Sept. 2006. 
13. A.G.Kalinichev, X.Xu, R.J.Kirkpatrick, Molecular dynamics simulation of water at mineral surfaces: Structure, dynamics, energetics and hydrogen bonding, AGU 2006 Fall Meeting, Abstr. B32B-07, San Francisco, CA, December 2006.

14. R.J.Kirkpatrick, A.G.Kalinichev, B.L.Phillips, MD computer simulations of the structure and dynamics of water in the interlayers of 10- $\AA$ phase, AGU 2006 Fall Meeting, Abstr. V41D-1766, San Francisco, CA, December 2006.

15. I.S.Ufimtsev, A.G.Kalinichev, T.J.Martinez, R.J.Kirkpatrick, Multi-state empirical valence bond MD modeling of hydroxyl ion transfer in aqueous environments, AGU 2006 Fall Meeting, Abstr. MR53C-0993, San Francisco, CA, December 2006.

16. Kumar, P., Kalinichev, A.G., and Kirkpatrick, R.J., The molecular mechanism and energetics of carbonic acid dissociation in aqueous environment studied by ab initio molecular dynamics and metadynamics computer simulations, AGU 2006 Fall Meeting, Abstr. V53D-1782, San Francisco, CA, December 2006.

17. G.M.Bowers, R.J.Kirkpatrick., Ion dynamics at the quartz-water and clay-water interfaces, 233rd Amer. Chem. Soc. National Meeting, Abstr. 28-GEOC, Chicago, IL, March 2007.

18. A.G.Kalinichev, Y.E.Gorbaty, G.V.Bondarenko, R.J.Kirkpatrick, Hydration structure of $\mathrm{Na}^{+}$and $\mathrm{Cl}^{-}$ions from ambient to supercritical conditions, 233rd Amer. Chem. Soc. National Meeting, Abstr. 127-SUST, Chicago, IL, March 2007.

19. Kumar, P., Kalinichev, A.G., and Kirkpatrick, R.J., Structure and hydrogen bonding of monocarboxylic acids intercalated in layered double hydroxides. 233rd Amer. Chem. Soc. National Meeting, Abstr. INOR-1048, Chicago, IL, March 2007.

20. I.S.Ufimtsev, A.G.Kalinichev, T.J.Martinez, R.J.Kirkpatrick, A charged ring model for hydroxide ion (aq) simulation, 233rd Amer. Chem. Soc. National Meeting, Abstr. INOR-1041, Chicago, IL, March 2007.

21. W.-Y.Ahn, A.G.Kalinichev, M.M.Clark, Molecular dynamics simulations of the NOM adsorption on polymeric membrane surface in the presence of metal ions, 233rd Amer. Chem. Soc. National Meeting, Abstr. 61-SUST, Chicago, IL, March 2007.

22. G.M.Bowers, R.J.Kirkpatrick. ${ }^{39} \mathrm{~K}$ NMR investigation of potassium binding and dynamics on hectorite, 44th Annual Meeting of the Clay Mineral Society, Santa Fe, NM, June 2007.

23. R.J.Kirkpatrick, P.Kumar., A.G.Kalinichev, Q.Li, M.X.Reinholdt, Molecular dynamics modeling and experimental studies of layered double hydroxides intercalated with carboxylic and amino acids, 44th Annual Meeting of the Clay Mineral Society, Santa Fe, NM, June 2007.

24. A.G.Kalinichev, G.M.Bowers, R.J.Kirkpatrick, Dynamics of Aqueous Species at Interfaces with Hydroxylated Mineral Surfaces: MD Simulation and NMR Spectroscopy, 44th Annual Meeting of the Clay Mineral Society, Santa Fe, NM, June 2007.

\section{Invited Lectures}

1. Kirkpatrick, R.J., invited, Computational and experimental studies of layered double hydroxides, Department of Chemistry, Marquette University, Milwaukee, WI, February 2006

2. Kirkpatrick, R.J., invited, Molecular modeling studies of mineral interlayers and mineral-water interfaces, Department of Geological Sciences and Center for Environmental Molecular Science, SUNY Stony Brook, March 2006.

3. Kalinichev, A.G., invited, Molecular modeling of aqueous solutions and substrate-solution interfaces, 1st Workshop on Molecular Modeling Fundamentals in Water Treatment Applications, Portal, AZ, April 2006.

4. Kalinichev, A.G., invited, Molecular dynamics computer simulations of aqueous mineral interfaces and interlayers, IPNS Seminar, Argonne National Laboratory, Argonne, IL, June 2006.

5. Kirkpatrick, R.J., invited, Molecular modeling and NMR spectroscopy of mineral-fluid interactions, Shell Oil Company Symposium on Industry-University Interactions, June 2006.

6. Kirkpatrick, R.J., invited, Molecular modeling and NMR spectroscopy of mineral-fluid interactions, ExxonMobil Research Laboratories, Houston, TX, June 2006.

7. Kalinichev, A.G., invited, Molecular modeling of mineral-water interfaces, Nalco Chemical Co., Naperville, IL, June 2006.

8. Kirkpatrick, R.J., invited, NMR and molecular modeling studies in environmental mineralogy: Mineral surface 
and interlayer studies, Institut de Minéralogie et de Physique des Milieux Condensés, Paris, September 2006.

9. Kirkpatrick, R.J., invited, NMR and Molecular modeling studies of fluid-solid interfaces, Laboratoire de Physique de la Matière Condensèe, Ecole Polytechnique, Palaiseau, France, September 2006

10. Kalinichev, A.G., invited, Molecular dynamics computer simulations of cement phases using the CLAYFF force field - MIT-France Workshop on Cement Science, Cambridge, MA, January 2007.

11. Kalinichev, A.G., invited, Molecular scale structure and dynamics of geologically important aqueous fluids and mineral-fluid interfaces - US DOE Office of Basic Energy Sciences Topical Research Symposium “Computational Geosciences”, Gaithersburg, MD, May 2007.

12. Kirkpatrick, R.J., invited, Innovation in use and research on cementitious materials, atomic and molecular scale computational modelling in cement science, Plenary Lecture, 12th International Congress on the Chemistry of Cement, Montreal, July 2007.

13. Kalinichev, A.G., invited, Molecular dynamics computer simulations of water at mineral interfaces and in nanoconfinement - 3rd Annual Cornell Nanoscale Facility Fall Workshop, "Defining the Interface between Nanoscience and Geology", Cornell University, Ithaca, NY, November 2007.

14. Kalinichev, A.G., invited, Structure and dynamics of aqueous mineral interfaces and interlayers: Computational molecular modeling approach - The Alumni / Shell Oil Company Distinguished Lecture Series, Department of Geological Sciences, Michigan State University, East Lansing, MI, November 2007.

\section{Overview of Research Results for 2006-2007}

\section{Water and Cation and Anion Dynamics at the Quartz/Water Interface: Experimental Studies}

Sum frequency vibrational spectroscopic (SFVS) study of the $\mathrm{pH}$ dependence of water structure at the quartz surface has suggested a highly ordered water arrangement with the orientation of the $\mathrm{H}_{2} \mathrm{O}$ molecules changing with $\mathrm{pH}$ (Ostroverkhov et al., 2004, 2005). Our ongoing MD simulations and ${ }^{23} \mathrm{Na}$ and ${ }^{35} \mathrm{Cl} \mathrm{NMR}$ study of sodium and chloride interactions with the surface of quartz, however, reveal a somewhat different situation. The MD studies show a dynamically disordered interfacial water structure without areas of highly ordered $\mathrm{H}_{2} \mathrm{O}$. The NMR results show that both $\mathrm{Na}^{+}$and $\mathrm{Cl}^{-}$, which were present in the solutions used for the SFVS experiments, are associated with the surface and that their behavior does not change between $\mathrm{pH}$ 3 and 10.5. Both $\mathrm{Na}^{+}$and $\mathrm{Cl}^{-}$are in rapid dynamical exchange between surface-sorbed and solution-like states and exhibit increased $T_{1}$ relaxation rates in the presence of quartz that do not vary from $\mathrm{pH} 3$ to 10.5 (Figure 1).

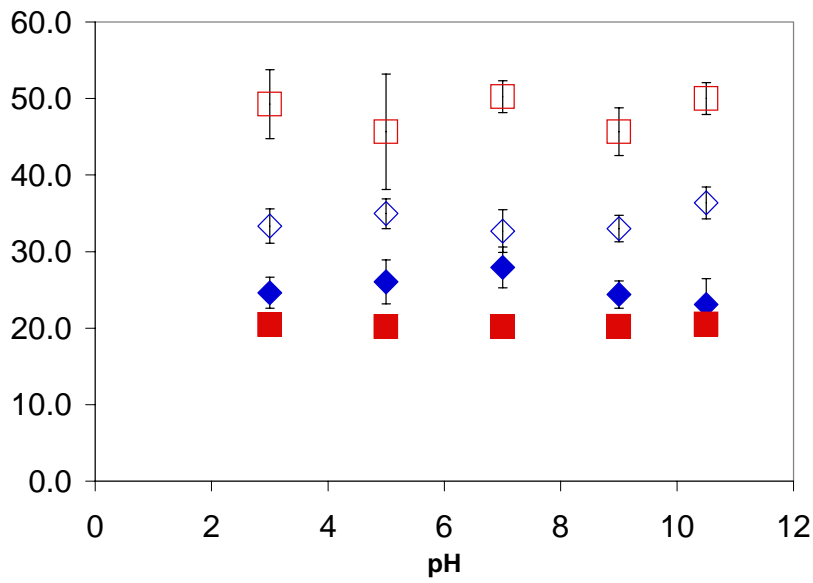

Fiqure 1. $T_{1}$ relaxation rates for ${ }^{23} \mathrm{Na}$ (red squares) and ${ }^{35} \mathrm{Cl}$ (blue diamonds) in neat solutions of constant $0.01 \mathrm{M}$ ionic strength (filled symbols) and mixtures of the solution with quartz powder at a solid-to-solution ratio of 1:1 (open symbols). 
An increase in the relaxation rate with respect to bulk solution is typically observed for mobile quadrupolar nuclei that are associated with a surface (Mason 1987; Yu and Kirkpatrick 2001; Xu and Kirkpatrick 2006). The data are consistent with a slowly varying zero point charge for quartz, meaning that the quartz surface remains almost fully hydroxylated and of neutral charge from $\mathrm{pH} 3$ to 10.5. A long MD simulation of a fully hydroxylated quartz interface in $\mathrm{NaCl}$ solution has been completed to quantify the dynamics of $\mathrm{H}_{2} \mathrm{O}, \mathrm{Na}^{+}$, and $\mathrm{Cl}^{-}$on a time scale up to 1 ns (see below). We conclude that the changes in SFVS spectra attributed to a $\mathrm{pH}$ dependent alteration in the degree of surface hydroxylation and subsequent reorientation of water near the surface are in fact related to variation in the $\mathrm{Na}^{+}$and $\mathrm{Cl}^{-}$counterion concentration in solution as the $\mathrm{pH}$ is adjusted with $\mathrm{NaOH}$ and $\mathrm{HCl}$.

\section{Water and Alkali Cation Dynamics in and on Layer Silicates: Experimental Studies}

Much of our experimental work has focused on understanding water and cation dynamics at surfaces and in nano-confined spaces of micas and clays, with specific focus on evaluating previous computational and experimental results. ${ }^{39} \mathrm{~K}$ and ${ }^{2} \mathrm{H}$ NMR studies of K-exchanged smectite clay (hectorite) show that water and cation motion are closely coupled in the interlayer (Bowers et al. 2008). Previous molecular modeling and experimental studies support the formation of ordered water in interlayers and near mineral surfaces (Cruz et al. 1978; Ishimaru and Ikeda 1999; Greathouse et al. 2000; Wang et al. 2001; Wang et al. 2003; Benesi et al. 2004; Wang et al. 2004; Benesi et al. 2005; Kalinichev and Kirkpatrick 2005; Kirkpatrick et al. 2005; Wang et al. 2005; Wang et al. 2006; Kalinichev et al. 2007). However, there have been few spectroscopic studies of $\mathrm{K}^{+}$dynamic behavior and the coupling between water and ion motion at these water/mineral interfaces. Knowledge regarding these dynamics and dynamic couplings is fundamental to our understanding of water and ion structure and dynamics near surfaces.

The results for K-hectorite (Figure 2) show $\mathrm{K}^{+}$and $\mathrm{H}_{2} \mathrm{O}$ motion occur in a $1 / 1.5$ by weight $\mathrm{K}$-hectorite/water paste throughout the temperature range from $-50^{\circ} \mathrm{C}$ to $40^{\circ} \mathrm{C}$ with evidence of a melting transition for both species near $0^{\circ} \mathrm{C}$. XRD of the paste at $100 \%$ relative humidity (R.H.)reveal a distribution of layer spacings with the predominant species a $12.5 \AA$ phase, which has a gallery height suitable for two mixed $\mathrm{K}^{+} / \mathrm{H}_{2} \mathrm{O}$ layers in the interlayer. Above the melting transition, narrowing of the ${ }^{39} \mathrm{~K}$ NMR spectra and the observed relationship between $T_{1}$ and $T_{2}$ relaxation behavior indicate $\mathrm{K}^{+}$motion at a rate of the order of the Larmor frequency (27 MHz) or faster. The nutation rate, quadrupolar product, and magnitude of the $T_{1}$ relaxation rate above the melting transition show the presence of residual ${ }^{39} \mathrm{~K}$ quadrupolar coupling. These results suggest fast $\mathrm{K}^{+}$exchange between anisotropic binding environments, consistent with the $>5,000 \mathrm{MHz} \mathrm{K}^{+}$hopping between inner-sphere and outer-sphere coordination environments observed in MD simulations of $12.5 \AA$ K-montmorillonite at $300 \mathrm{~K}$ (Chang et al., 1998). Below the melting transition, there is an increase in the ${ }^{39} \mathrm{~K}$ NMR signal-to-noise ratio with increasing temperature associated with either slow motion of confined and surface $\mathrm{K}^{+}$or the motion of coordinating $\mathrm{H}_{2} \mathrm{O}$ molecules. At no point is a separate resonance associated with surface $\mathrm{K}^{+}$ observed despite $30 \%$ of the ${ }^{39} \mathrm{~K}$ spins being located at the surface This observation suggests that the coordination environments and dynamics of surface and confined $\mathrm{K}^{+}$are similar.

There are two NMR-distinguishable $\mathrm{H}_{2} \mathrm{O}$ environments in the hectorite paste. One broad ${ }^{2} \mathrm{H}$ resonance at $-50^{\circ} \mathrm{C}$ is structurally and dynamically similar to free water, and we interpret it to represent water external to the clay particles. A second, narrow resonance is associated with confined $\mathrm{H}_{2} \mathrm{O}$ that exhibits restricted motion below $10^{\circ} \mathrm{C}$. Simulations of the narrow ${ }^{2} \mathrm{H}$ NMR 
lineshape below the melting transition show that confined $\mathrm{H}_{2} \mathrm{O}$ experiences fast $(>2 \mathrm{MHz})$ rotation about the molecular dipole axis, which has been observed in other clays (Conard et al., 1984; Cruz et al., 1978; Ishamaru and Ikeda, 1999; Sanz et al., 2006). Above the melting transition, isotropic and near-isotropic ${ }^{2} \mathrm{H}$ peaks are observed (Figure 3). The broader peak is likely associated with confined $\mathrm{H}_{2} \mathrm{O}$ diffusing in the interlayer where clay/ion $/ \mathrm{H}_{2} \mathrm{O}$ interactions introduce residual ${ }^{2} \mathrm{H}$ quadrupolar coupling. The second, extremely narrow peak is associated with freely diffusing bulk $\mathrm{H}_{2} \mathrm{O}$. There may also be exchange between confined $\mathrm{H}_{2} \mathrm{O}$ near particle edges and free $\mathrm{H}_{2} \mathrm{O}$ contributing intensity to these peaks. Calculations based on surface area and the diffusion coefficient of $\mathrm{H}_{2} \mathrm{O}$ confined in a $12.5 \AA \mathrm{K}$-montmorillonite phase confirm that not all confined $\mathrm{H}_{2} \mathrm{O}$ molecules can exchange with free $\mathrm{H}_{2} \mathrm{O}$ during our NMR experiments. The increase in relative intensity of the confined $\mathrm{H}_{2} \mathrm{O}$ resonance with temperature may be an entropic response of the system as the temperature increases. The specific types of motion for both $\mathrm{K}^{+}$ and $\mathrm{H}_{2} \mathrm{O}$ are difficult to distinguish with NMR and are best studied with molecular dynamics simulations. Such studies are planned for the future. The similar temperature-dependent behavior of $\mathrm{K}^{+}$and $\mathrm{H}_{2} \mathrm{O}$ in this system suggests a link between the dynamics of these species, which has important implications for NMR studies of ion dynamics in confined environments.

(a)
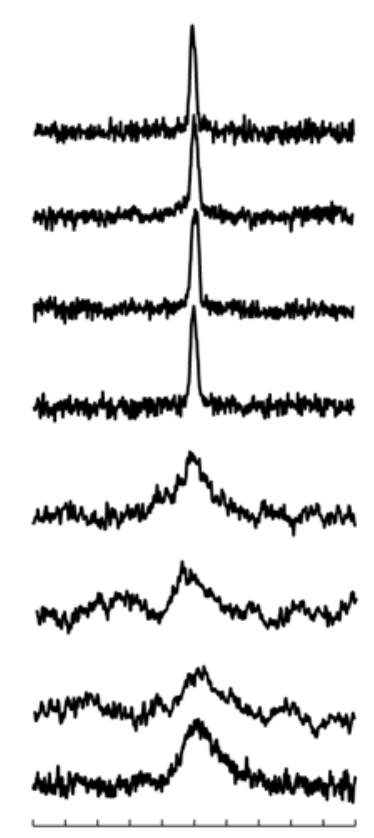

$\begin{array}{lllll}50 & 25 & 0 & -25 & -50\end{array}$

Frequency $(\mathrm{kHz}$ from $1 \mathrm{M} \mathrm{KCl}(\mathrm{aq}))$ (b)

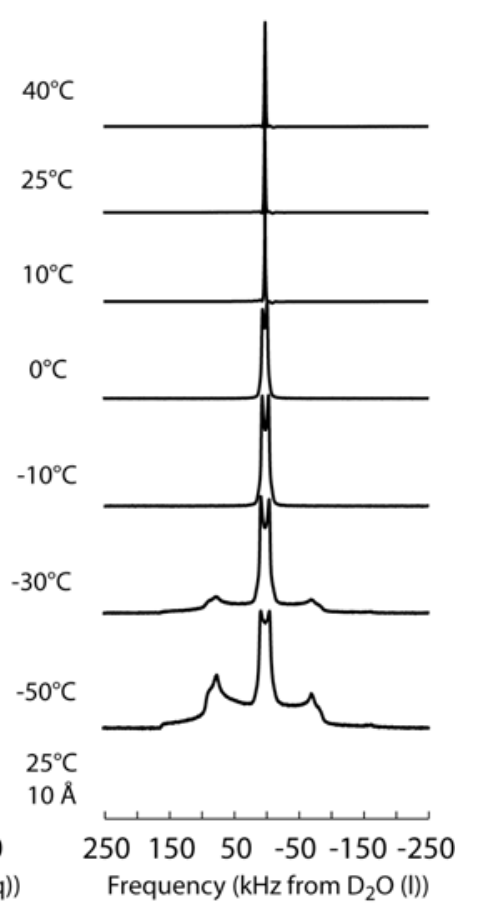

Fiqure 3. Close-up of the ${ }^{2} \mathrm{H}$ NMR spectra above the melting transition in the $1 / 1.5$ wt. Khectorite/water paste. Note the increasing relative intensity of the broader peak with increasing temperature.

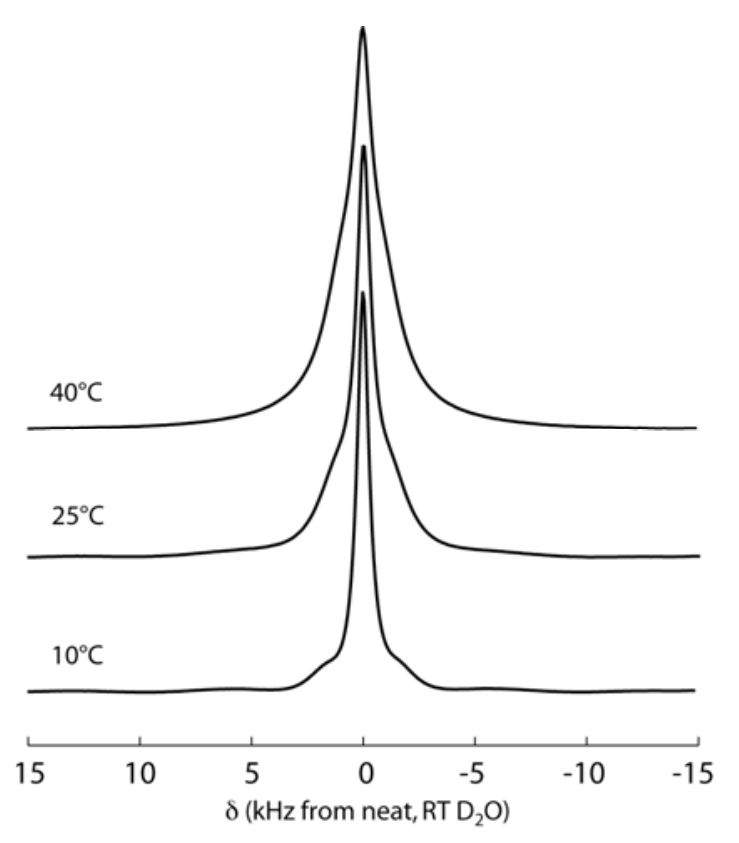

Figure 2. ${ }^{39} \mathrm{~K}$ (column a) and ${ }^{2} \mathrm{H}$ (column b) VT NMR spectra of a 1/1.5 wt ratio K-hectorite/water mixture. The bottom spectrum in column (a) is the ${ }^{39} \mathrm{~K}$ NMR spectrum of a $10 \AA$ K-hectorite phase equilibrated with the atmosphere and acquired at room temperature $\left(\sim 25^{\circ} \mathrm{C}\right)$. 
For synthetic illite/smectite in water at pHs of 1 and $3,{ }^{39} \mathrm{~K},{ }^{27} \mathrm{Al}$, and ${ }^{29} \mathrm{Si}$ NMR show evidence of liquid-like ${ }^{39} \mathrm{~K}$ displaced from the mineral surface without any dissolution of the parent material. Central transition selective ${ }^{39} \mathrm{~K}$ echo-type NMR experiments of ambient airequilibrated illite/smectite and $1 / 1$ by weight $\mathrm{pH}=3$ and $\mathrm{pH}=1$ suspensions reveal a resonance similar to that of hectorite and muscovite (Stebbins et al., 2002), suggesting predominantly rigid interlayer $\mathrm{K}^{+}$in this material. The spectrum from the $\mathrm{pH}=1$ suspension also contains a sharp, liquid-like signal above the rigid ${ }^{39} \mathrm{~K}$ resonance. Echo experiments selective for mobile, liquidlike ${ }^{39} \mathrm{~K}$ show the presence of a strong, sharp NMR signal in the $\mathrm{pH}=1$ suspension and a broad resonance in the $\mathrm{pH}=3$ suspension. The sharp resonance for the $\mathrm{pH}=1$ suspension is clear evidence of mobilized $\mathrm{K}^{+}$in this system. We also observe a decrease in the $T_{2}$ relaxation rate of ${ }^{39} \mathrm{~K}$ in both suspensions compared to air--equilibrated illite/smectite. It is possible that these results reflect illite/smectite dissolution rather than $\mathrm{K}^{+}$displacement by $\mathrm{H}_{3} \mathrm{O}^{+}$, and therefore but ${ }^{29} \mathrm{Si}$ and ${ }^{27} \mathrm{Al}$ MAS NMR spectra of the solid samples show no detectable structural changes to the illite/smectite or new phases formed by incongruent dissolution.. Additional studies are necessary to confirm this assessment and test whether the hydronium concentration or the presence of $\mathrm{H}_{2} \mathrm{O}$ is the source of the observed $T_{2}$ /spectral variation. These studies will be completed in the remainder of the current funding year.

\section{Nuclear Magnetic Resonance Studies of Arsenic in the Environment: Experimental Studies}

${ }^{75}$ As is a very difficult nucleus to study with NMR due to its very large quadrupole moment, but the structural and dynamical information provided by NMR is of potentially great use in studies of arsenic speciation and transport in the environment. Our results (Bowers and Kirkpatrick; paper 14 of Table 1) provide the first insight into how best to acquire ${ }^{75}$ As NMR spectra of arsenate and arsenite oxyanion compounds and how the chemical shift is related to structure. To acquire the spectra, we introduced a new experimental approach that allows more efficient acquisition of central transition resonances several 10's of $\mathrm{MHz}$ in width than traditional techniques. This method combines the histogram acquisition approach of Hari et al. (1997) and the sensitivity enhancing properties of the so-called QCPMG pulse sequence (Garroway 1977; Cheng and Ellis 1989; Larsen et al. 1997). The dominance of the quadrupolar interaction in ${ }^{75}$ As NMR is clear from the NMR parameters (Table 3) extracted from spectra acquired using the 17.6 T and 21.1 T spectrometers at the High Field Magnetic Resonance User Facility at the DOE Pacific Northwest National Laboratory and the $14.1 \mathrm{~T}$ spectrometer at the University of Illinois. However, for arsenate oxyanions in crystalline salts and oxides, we identified a linear relationship between the ${ }^{75}$ As isotropic chemical shift and the electronegativity of the next-nearest neighbor cation. This result suggests that the isotropic chemical shift can directly distinguish between inner-sphere and outer-sphere arsenate sorption, because innersphere sorption will alter the identity of the next-nearest neighbor cation.

Table 3. ${ }^{75}$ As NMR parameters for the arsenate compounds.

\begin{tabular}{cccccc}
\hline Sample/Resonance & $C_{q}(\mathrm{MHz})$ & $\eta_{q}$ & $\delta_{\text {iso }}(\mathrm{ppm})$ & $\delta_{\text {aniso }}(\mathrm{ppm})$ & $\eta_{c s}$ \\
\hline $\mathrm{Li}_{3} \mathrm{AsO}_{4}$ & $2.85 \pm 0.10$ & $1.0 \pm 0.05$ & $384 \pm 8$ & - & - \\
$\mathrm{CsH}_{2} \mathrm{AsO}_{4}$ & $5.12 \pm 0.22$ & $0.05 \pm 0.05$ & $367 \pm 5$ & $-49 \pm 20$ & $1 \pm 0.1$ \\
$\mathrm{As}_{2} \mathrm{O}_{5}-\mathrm{Tet} . \mathrm{As}$ & $21.3 \pm 0.2$ & $0.38 \pm 0.07$ & $273 \pm 28$ & - & - \\
$\mathrm{As}_{2} \mathrm{O}_{5}-$ Oct. As & $17.5 \pm 0.4$ & $1.0 \pm 0.05$ & $0 \pm 10$ & - & - \\
$\mathrm{Ca}_{3}\left(\mathrm{AsO}_{4}\right)_{2} \cdot 8 \mathrm{H}_{2} \mathrm{O}$ & $57 \pm 1$ & $0.74 \pm 0.04$ & $779 \pm 300$ & - & - \\
\hline
\end{tabular}


Inelastic and Quasielastic Neutron Scattering of Nano-Confined Water in Minerals: Experimental Studies

Neutron scattering methods can provide important, direct information about water dynamics that is highly complementary to NMR and computational modeling results. Inelastic scattering probes the rotational and vibrational dynamics of water and $-\mathrm{OH}$, and quasielestic scattering probes water diffusion. We are continuing a series of neutron scattering experiments at the HRMECS and QENS instruments of the IPNS facility at Argonne National Laboratory and at NIST to investigate the vibrational and diffusional dynamics of $\mathrm{H}_{2} \mathrm{O}$ molecules confined in mineral interlayers. To date, two samples of hydrocalumite (dehydrated and fully hydrated) have been studied over a range of temperatures below and above the interlayer phase transition, which is expected to be near $\sim 300 \mathrm{~K}$ (Kirkpatrick et al., 1999; Kalinichev et al., 2000; Andersen, 2002). Figures 4 and 5 illustrate the data obtained at three different neutron scattering instruments.

The fully hydrated sample shows significant differences in the librational spectral modes below and above the phase transition (Fig.4), and quasi-elastic spectral broadening is also clearly visible above the phase transition temperature between 303 and $308 \mathrm{~K}$ (light green and dark green lines in Fig.5, respectively). These first results demonstrate the capabilities of neutron scattering techniques to capture the details of the librational and diffusional motions of $\mathrm{H}_{2} \mathrm{O}$ depending on the degree to which the interlayer water molecules are orientationally ordered below and above the phase transition.

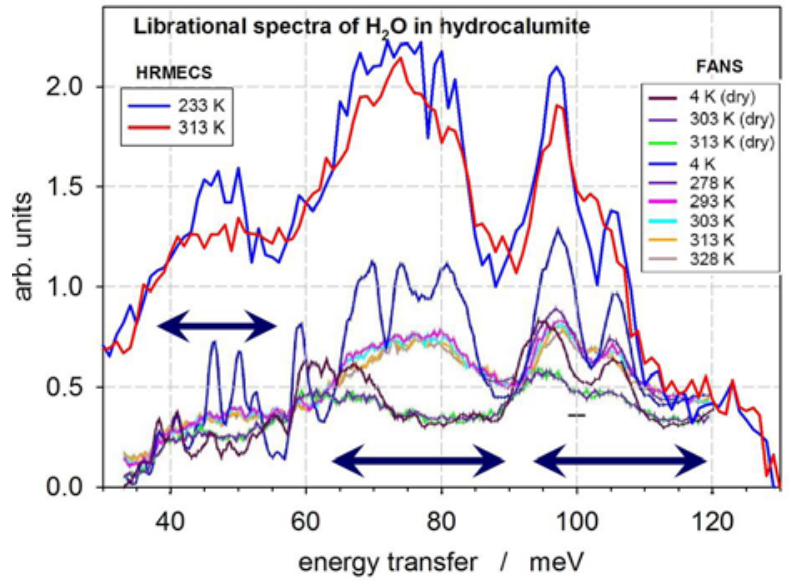

Fiqure 4. A combination of MD simulations with INS measurements for hydrocalumite helps to uniquely identify three energy ranges characteristic to the librational modes of $\mathrm{H}_{2} \mathrm{O}$ in the interlayers

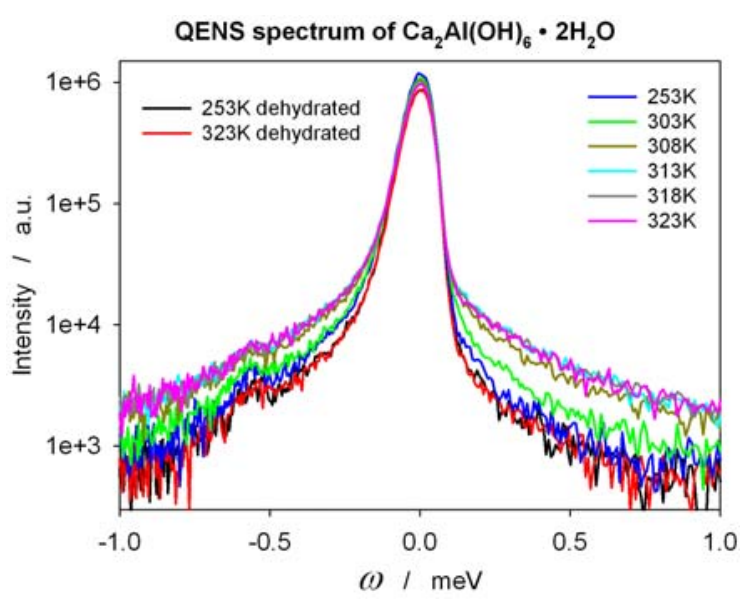

Figure 5. Quasi-elastic neutron scattering spectra of the dehydrated and hydrated samples of hydrocalumite below and above the interlayer phase transition.

\section{Molecular Dynamics Computer Simulations of Nano-Confined and Interfacial Aqueous Fluids}

In 2007, we performed several especially long MD simulation runs to better understand the dynamic behavior of interfacial aqueous species on time scales from sub-ps to ns for minerals with varying surface structures that were also investigated by NMR spectroscopy. To help interpret the NMR results for quartz described above, one simulation looked at the neutral 
hydroxylated (001) surface of quartz, which contains only -OH sites. The results show that both $\mathrm{Na}^{+}$and $\mathrm{Cl}^{-}$are associated with the surface as outer sphere complexes, in agreement with the NMR results, and that H-bond donation and acceptance between surface sites and water molecules provides structuring of the first water layer. There are no long-lived, highly structured regions, however, and the diffusion coefficient of surface-associated $\mathrm{H}_{2} \mathrm{O}$ is less then an order of magnitude slower than in bulk liquid water (Fig.6b). $\mathrm{Na}^{+}$and $\mathrm{Cl}^{-}$adsorb and desorb from the surface on the time scale of $\sim 100 \mathrm{ps}$, also in good agreement with the ${ }^{23} \mathrm{Na}$ and ${ }^{35} \mathrm{Cl} \mathrm{NMR}$ spectra and relaxation measurements discussed above.

In contrast, the (001) surface of the chain-structure Ca-silicate, tobermorite, affects the interfacial water structure and dynamics much more strongly. This is because the tobermorite surface contains both $-\mathrm{OH}$ and $-\mathrm{O}^{-}$that provide stronger binding sites. In a simulation with 0.25 $\mathrm{M} \mathrm{KCl}$ aqueous solution, we are able to effectively distinguish $\mathrm{H}_{2} \mathrm{O}$ molecules that spend most of their time within channels between tetrahedral chains on the surface and adsorbed $\mathrm{H}_{2} \mathrm{O}$ molecules residing right above the interface. Within the channels, $\mathrm{H}_{2} \mathrm{O}$ molecules donate $\mathrm{H}$ bonds to both the bridging and non-bridging oxygens of the bridging Si-tetrahedra as well as to other $\mathrm{H}_{2} \mathrm{O}$. Some of the molecules form strong $\mathrm{H}$-bonds persisting over $100 \mathrm{ps}$ and longer, but many others undergo librations and occasional diffusional jumps from one surface site to another. The average diffusion coefficients of the surface-associated $\mathrm{H}_{2} \mathrm{O}$ molecules that spend most of their time in the channels and those that lie above the nominal interface differ by about an order of magnitude $\left(D_{\mathrm{H} 2 \mathrm{O}}=5.0 \times 10^{-7} \mathrm{~cm}^{2} / \mathrm{s}\right.$ and $D_{\mathrm{H} 2 \mathrm{O}}=6.0 \times 10^{-6} \mathrm{~cm}^{2} / \mathrm{s}$, respectively). The average diffusion coefficient for all surface-associated $\mathrm{H}_{2} \mathrm{O}$ molecules is about $1.0 \times 10^{-6} \mathrm{~cm}^{2} / \mathrm{s}$. All of these values are significantly less than the value of $2.3 \times 10^{-5} \mathrm{~cm}^{2} / \mathrm{s}$ characteristic of $\mathrm{H}_{2} \mathrm{O}$ molecules in the bulk liquid, but are in good quantitative agreement with ${ }^{1} \mathrm{H}$ NMR results for surface-associated water in Ca-silicate cements (Korb et al, 2007; paper 13 of Table 1).

(a)

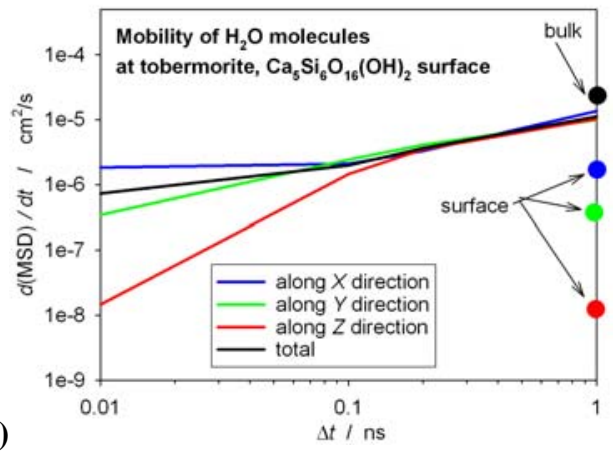

(b)

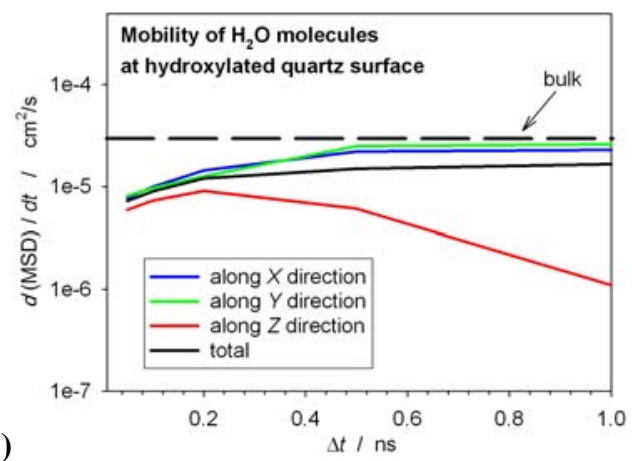

Figure 6. Apparent diffusional mobility of water molecules at the surfaces of quartz (b) and tobermorite (a) as functions of the length of the MD trajectory averaging. Colored dots indicate the mobility of the molecules strongly adsorbed at the surface of tobermorite for $>1 \mathrm{~ns}$.

\section{Computational Modeling of Proton Exchange Reaction in Aqueous Systems}

$\mathrm{H}$-exchange reactions are critical to understanding the structure and dynamics at mineral surfaces and near dissolved oxy-anions, but are difficult to model with classical MD methods. Our new computational directions are focused on developing modeling capabilities for these reactions using $a b$ initio molecular dynamics (AIMD), metadynamics, and multi-state empirical valence bond (MS-EVB) approaches. 
As the first step in exploring the use of MS-EVB in water-mineral systems, we have developed an MS-EVB force field to study the solvation and dynamics of hydrated $\mathrm{OH}^{-}$ions and the dynamics of proton hole exchange between $\mathrm{H}_{2} \mathrm{O}$ molecules. $\mathrm{OH}^{-}$ion plays a central role in many reactions but has been difficult to model in classical MD simulations. The empirical parameters of the MS-EVB Hamiltonian matrix elements are fitted to reproduce the potential energy surface of the $\mathrm{H}_{3} \mathrm{O}_{2}{ }^{-}$dimer obtained from quantum mechanical calculations as well as geometries and energies of small hydrated $\left(\mathrm{H}_{2} \mathrm{O}\right)_{n} \mathrm{OH}^{-}$clusters. As part of this work, we developed a novel "charged-ring” model of $\mathrm{OH}^{-}(\mathrm{aq})$ for classical MD simulations (Fig. 7), which represents the structure and dynamics of the hydrated $\mathrm{OH}^{-}$ion much more accurately than any previous classical models (Ufimtsev et al., 2007, 2008; paper 10 of Table 1).

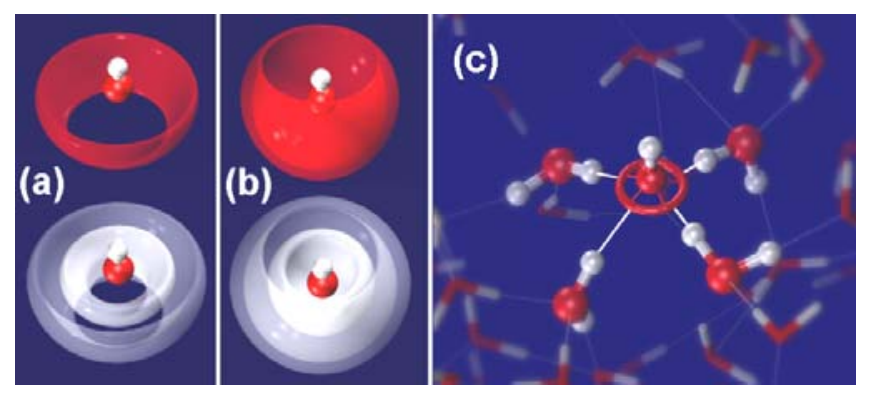

Fiqure 7. Panels (a),(b): spatial distribution functions of the oxygen (red) and hydrogen (white) atoms of the first hydration shell $\mathrm{H}_{2} \mathrm{O}$ molecules around (a) charged-ring, (b) point-charge $\mathrm{OH}^{-}$ion models. The isosurfaces cover regions where the density of atoms is $60 \%$ greater than that of bulk water. Panel (c): a simulation snapshot displaying 4coordinated hydroxide ion in the charged-ring simulation.

Carbonate minerals and solution carbonate species also play many key geochemical roles, but little is known about their molecular scale reactivity. We have investigated the dissociation reaction pathways and energetics of carbonic acid $\left(\mathrm{H}_{2} \mathrm{CO}_{3}\right)$ in the gas phase and in aqueous solution using AIMD and metadynamics computer simulations (Kumar et al., 2007a; paper 8 of Table 1). Significant rearrangements in the $\mathrm{H}_{2} \mathrm{CO}_{3}$ hydration shell during its conformational changes require a cooperative mechanism that involves a larger number of relatively low-energy barriers, compared to the gas-phase dissociation, which involves a cooperative mechanism with a single barrier. $\mathrm{H}_{2} \mathrm{CO}_{3}$ makes strong $\mathrm{H}$-bonds with $\mathrm{H}_{2} \mathrm{O}$ molecules, and occasionally protons are exchanged between them. This behavior is consistent with the tendency of $\mathrm{H}_{2} \mathrm{CO}_{3}$ to form bicarbonate ion under ambient conditions. Ongoing work is focusing on the solvation structure of $\mathrm{H}_{2} \mathrm{CO}_{3}, \mathrm{HCO}_{3}{ }^{-}, \mathrm{CO}_{3}{ }^{-2}$ and $\mathrm{CO}_{2}$ and the dissociation energetics of $\mathrm{HCO}_{3}{ }^{-}$in solution.

The metadynamics CPMD results for the dissociation of $\mathrm{H}_{2} \mathrm{CO}_{3}$ in aqueous solution (e.g., Figure 8) show that the two lowest energy conformers, transtrans and cis-trans, dissociate by a two-step process:

(1) $\mathrm{H}_{2} \mathrm{CO}_{3} \rightarrow \mathrm{HCO}_{3}^{-}+\mathrm{H}^{+}$(aq.) - the deprotonation of carbonic acid to bicarbonate;

(2) $\mathrm{HCO}_{3}^{-} \rightarrow \mathrm{CO}_{2}+\mathrm{OH}^{-}$(aq.) - the dehydroxylation of bicarbonate.

This result is in contrast to the gas-phase dissociation, which involves a cooperative mechanism with a single energy barrier for the reaction $\mathrm{H}_{2} \mathrm{CO}_{3} \rightarrow \mathrm{CO}_{2}+$ $\mathrm{H}_{2} \mathrm{O}$. The trans-trans conformer is more stable than

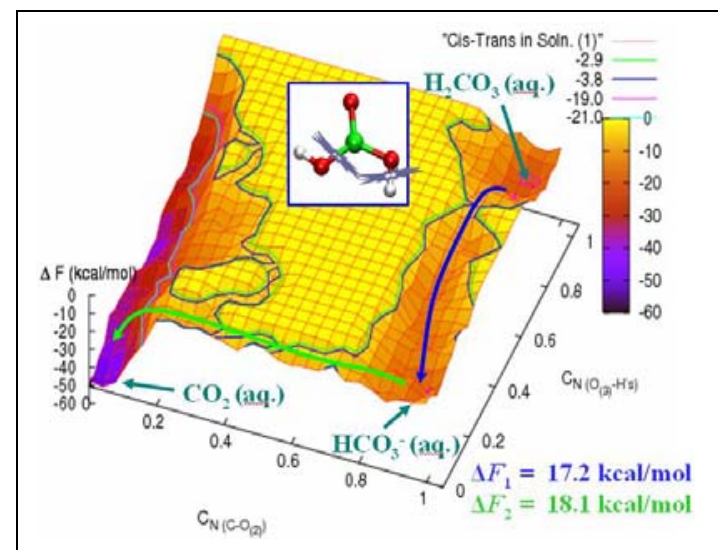

Fiqure 8. Free energy surface of cis-trans $\mathrm{H}_{2} \mathrm{CO}_{3}$ dissociation in aqueous solution. the cis-trans conformer with respect to the dissociation to carbon dioxide in both the gas phase and aqueous solution. The ease of dissociation of the cis-trans conformer in solution is due to 
availability of a short channel for proton transport (proton wire) between the two protonated "ends" of the carbonic acid molecule. This process involves proton hopping between water molecules. A manuscript summarizing these results is currently in print (Kumar et al., 2008).

NMR and MD Studies of Dissolved Metals and Anions with Natural Organic Matter (NOM)

The geochemical importance of natural organic matter (NOM) is being increasingly recognized, but it is very difficult to characterize. In our previous combined NMR and MD studies of the interaction of dissolved $\mathrm{Cs}^{+}$ and $\mathrm{Cl}^{-}$with NOM in aqueous solution (paper 5, Table 1), we demonstrated that the Cs-NOM interaction occurs principally by outer sphere association with carboxylic groups to a lesser extent with phenolic groups on the NOM, that the increasing $\mathrm{Cs}$ association with increasing $\mathrm{pH}$ is due to the $\mathrm{pH}$ dependent protonation/deprotonation of these groups, and that Cs diffusion and exchange are rapid on the

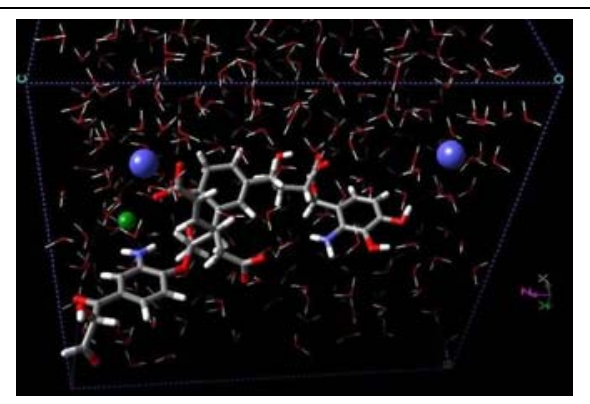

Fiqure 9. $\mathrm{Ca}^{2+}$ ion (left blue ball) inner-sphere coordinated to the NOM molecule in $0.2 \mathrm{~m}$ aqueous solution.

ca. $10^{4} \mathrm{~Hz}$ NMR time scale. In contrast, $\mathrm{Cl}^{-}$shows no detectable interaction with our NOM sample due to repulsive electrostatic interactions. The MD calculations provided key molecular scale structural and dynamical insight into the NMR results and confirmed our interpretation of the experimental results. MD simulation studies included the NOM interaction with other alkali and alkaline earth cations $\mathrm{Na}^{+}, \mathrm{Cs}^{+}, \mathrm{Mg}^{2+}$, and $\mathrm{Ca}^{2+}$ ) with the objective of more comprehensively understanding the structural-chemical controls of metal-NOM interactions. The MD simulation results (paper 9, Table 1 ) suggest that $\mathrm{Na}^{+}$forms only very weak outer-sphere complexes with $\mathrm{NOM}$, that $\mathrm{Mg}^{2+}$ interacts little with $\mathrm{NOM}$ due to its strongly held hydration shell, and that $\mathrm{Ca}^{2+}$ has the strongest association with NOM and forms inner-sphere complexes with NOM carboxylate groups (Figure 9). In all cases, cation-NOM binding occurs principally with carboxylate groups and to a lesser extent with phenolic and other - $\mathrm{R}-\mathrm{OH}$ groups. The diffusional mobility of NOM-bound cations is $~ 20 \%$ (NOM-Na ${ }^{+}$outer-sphere complex) to $~ 95 \%$ $\left(\mathrm{NOM}-\mathrm{Ca}^{2+}\right.$ inner-sphere complex) less than in bulk aqueous solution without NOM. These results support the idea that supramolecular, Ca-mediated aggregation of relatively small NOM molecules plays an important role in structuring organic compounds in natural aqueous environments.

We have further quantitatively investigated the structural, dynamical, and energetic effects of $\mathrm{Na}^{+}, \mathrm{Ca}^{2+}$ and $\mathrm{Mg}^{2+}$ on the supramolecular aggregation of $\mathrm{NOM}$ in aqueous solutions by MD simulations of much larger systems ( 100,000 atoms). These simulation systems included 8 individual dissolved NOM fragments and $12 \mathrm{Ca}^{2+}$ or $\mathrm{Mg}^{2+}$ ions $\left(24 \mathrm{Na}^{+}\right.$ions). The results are currently being analyzed in detail, and their preliminary interpretation is presented in Fig. 10. The results quantitatively confirm the predictions based on the earlier smaller-scale simulations (Sutton et al., 2005; Xu et al., 2006; Kalinichev and Kirkpatrick, 2007) that the supramolecular NOM aggregation in aqueous solutions is principally controlled by the strength of the cation-NOM binding, which occurs principally with the NOM carboxylate groups. This aggregation is relatively fast and can be observed in MD simulations on the time scale of just a few nanoseconds. MD simulations clearly demonstrate that the strength of the cation-NOM complexation follows a simple trend in terms of the charge/size ratio for the ions. Larger ions of the same charge $\left(\mathrm{Cs}^{+}\right.$vs. $\mathrm{Na}^{+}$, or $\mathrm{Ca}^{2+}$ vs. $\mathrm{Mg}^{2+}$ ) have a stronger tendency for NOM association, 
but for the ions of approximately the same size, higher charge results in a stronger association with NOM. Thus, in contrast to $\mathrm{Mg}^{2+}, \mathrm{Ca}^{2+}$ tends to form stronger inner-sphere complexes with NOM carboxylate groups, hence promoting supramolecular NOM aggregation in aqueous solutions.

(a)

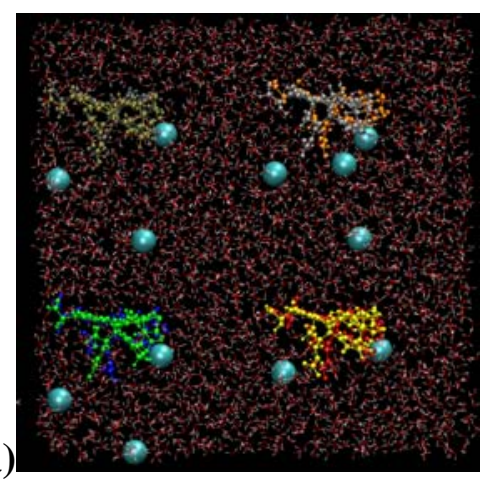

(b)

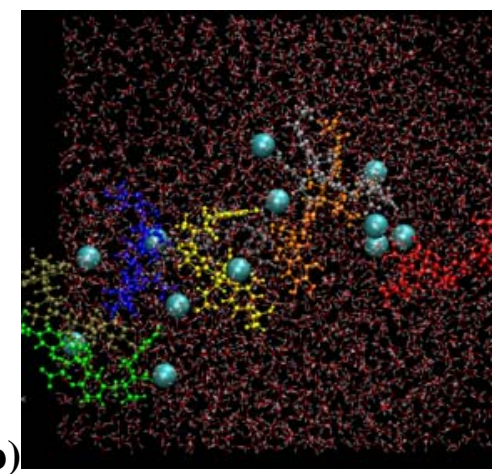

(c)

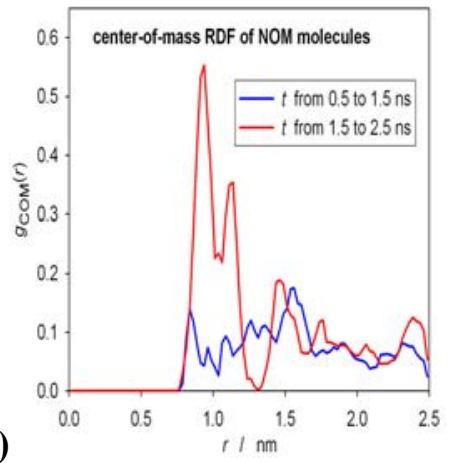

Fiqure 10. Snapshots of NOM-Ca ${ }^{2+}$ aqueous solutions: uniformly distributed in the solution in the pre-equilibrated initial state (a) and aggregated after 2.5ns of MD simulations (b). The time evolution of the center-of-mass radial distribution functions of the dissolved NOM molecules demonstrates a significant increase of the NOM aggregation with the characteristic length scale of $\sim 1 \mathrm{~nm}$ on the time scale of just a few ns.

\section{NMR and MD Studies of the Association of Amino Acids and Carboxylic Ions with Minerals}

In our previous work on the interaction amino acids and carboxylic species with minerals, we undertook experimental NMR studies of the amino acids glutamic acid and glutamine and the carboxylic acid citrate in layered double hydroxides (LDHs) and parallel computational MD studies of citrate, formate, acetate, and propionate in these compounds (papers 2, 4, and 11, Table 1). These studies showed that these species do not undergo ligand exchange reactions with LDHs and that the interaction is principally via electrostatic and van der Waals forces. Stabilization of hydrated LDH interlayer galleries containing these species is due to development of an integrated $\mathrm{H}$-bond network among the ions, water molecules and $\mathrm{OH}$-groups of the mineral surface. The organic species preferably accept $\mathrm{H}$-bonds from $\mathrm{H}_{2} \mathrm{O}$ molecules rather than from surface $\mathrm{OH}$-groups due to structural restrictions on the development of tetrahedrally coordinated $\mathrm{H}$-bonding environments for the $-\mathrm{COO}^{-}$groups at the surface.

In 2006-2007 we have extended these studies with a detailed experimental ${ }^{13} \mathrm{C}$ MAS NMR study of glutamate hydrotalcite (Mg,Al layered double hydroxide) that shows significantly larger $\mathrm{GA}^{-1} / \mathrm{GA}^{-2}$ ratios in the interlayer than in the bulk solution (paper 12, Table 1). For instance, at $\mathrm{pH} 11.0$, the $\mathrm{GA}^{-1} / \mathrm{GA}^{-2}$ ratio is 0.45 , an order of magnitude larger than that in solution. LDH phases normally prefer the more highly charged species, and the origin of this unusual behavior is not understood. Our current hypothesis is that it arises from a betterdeveloped interlayer H-bond network for the lower charged species than for the higher charge species. This hypothesis will be the basis for future MD modeling. 


\section{References}

Andersen, M.D., Jakobsen, H.J., Skibsted, J. (2002) Characterization of the $\alpha-\beta$ phase transition in Friedel's salt by variable temperature ${ }^{27} \mathrm{Al}$ MAS NMR spectroscopy. J. Phys. Chem. A 106: 6676-6682

Benesi, A. J., Grutzeck, M. W., O'Hare, B., Phair, J. W. (2004) Room temperature solid surface water with tetrahedral jumps of ${ }^{2} \mathrm{H}$ nuclei detected in ${ }^{2} \mathrm{H}_{2} \mathrm{O}$-hydrated porous silicates. J. Phys. Chem. B 108: 1778317790.

Benesi, A. J., Grutzeck, M.W., O'Hare, B., Phair, J. W. (2005) Room-temperature icelike water in kanemite detected by ${ }^{2} \mathrm{H}$ NMR $\mathrm{T}_{1}$ relaxation. Langmuir 21: 527-529.

Bowers, G.M. and Kirkpatrick R.J. (2007) High-field NMR study of arsenic oxysalts. Journal of Magnetic Resonance, 188, 311-321.

Bowers, G.M., Bish, D.L., Kirkpatrick, R.J. (2008) $\mathrm{H}_{2} \mathrm{O}$ and cation structure and dynamics in expandable clays: ${ }^{2} \mathrm{H}$ and ${ }^{39} \mathrm{~K}$ NMR investigations of hectorite. Journal of Physical Chemistry C, 112, 6430-6438.

Chang, F. R. C., Skipper, N. T., Sposito, G. (1998) Monte Carlo and molecular dynamics simulations of electrical double-layer structure in potassium-montmorillonite hydrates. Langmuir 14: 1201-1207.

Cheng, J. T. and Ellis, P.D. (1989) Adsorption of $\mathrm{Rb}^{+}$to gamma-alumina as followed by solid-state ${ }^{87} \mathrm{Rb}$ NMRspectroscopy. Journal of Physical Chemistry 93: 2549-2555.

Conard, J., Estrade-Szwarckopf, H., Dianoux, A. J., Poinsignon, C. (1984) Water dynamics in a planar lithium hydrate in the interlayer space of a swelling clay. A neutron scattering study. Journal de Physique 45: 13611367.

Cruz, M. I., Letellier, M., Fripiat, J.J. (1978) NMR study of adsorbed water. II. Molecular motions in the monolayer hydrate of halloysite. Journal of Chemical Physics 69: 2018-2027.

Garroway, A. N. (1977) Homogeneous and inhomogeneous nuclear spin echoes in organic solids: adamantane. Journal of Magnetic Resonance (1969-1992) 28(3): 365-71.

Greathouse, J. A., Refson, K., Sposito, G. (2000) Molecular dynamics simulation of water mobility in magnesiumsmectite hydrates. Journal of the American Chemical Society 122: 11459-11464.

Hari, P., Taylor, P.C., Kleinhammes, A., Kuhns, P.L., Moulton, W.G., Sullivan, N.S. (1997) Asymmetry in the local structural order in arsenic chalcogenide glasses: High field NMR in crystalline and glassy $\mathrm{As}_{2} \mathrm{Se}_{3}$. Solid State Communications 104(11): 669-672.

Ishimaru, S. and Ikeda, R. (1999) NMR studies on dynamics of water intercalated in clay minerals. Zeitschrift fuer Naturforschung, A: Physical Sciences 54(6/7): 431-436.

Kalinichev, A. G., Kirkpatrick, R. J., Cygan, R. T. (2000) Molecular modeling of the structure and dynamics of the interlayer and surface species of layered double hydroxides: chloride and water in hydrocalumite. American Mineralogist 85: 1046-1052.

Kalinichev, A. G. and Kirkpatrick, R.J. (2005) Molecular dynamics simulation of the water/alpha-quartz interface. Geochimica et Cosmochimica Acta 69(10): A510-A510.

Kalinichev, A. G. and Kirkpatrick, R.J. (2007) Molecular dynamics simulation of cationic complexation with natural organic matter. European Journal of Soil Science, 58: 909-917.

Kalinichev, A. G., Wang, J.W., Kirkpatrick, R.J. (2007) Molecular dynamics modeling of the structure, dynamics and energetics of mineral-water interfaces: Application to cement materials. Cement and Concrete Research 37(3): 337-347.

Kirkpatrick, R. J., Kalinichev, A.G., Wang, J. (2005) Molecular dynamics modelling of hydrated mineral interlayers and surfaces: structure and dynamics. Mineralogical Magazine 69(3): 289-308.

Kirkpatrick, R.J., Yu, P., Hou, X., Kim, Y. (1999) Interlayer structure, anion dynamics, and phase transitions in mixed-metal layered hydroxides: variable temperature 35Cl NMR spectroscopy of hydrotalcite and Caaluminate hydrate. American Mineralogist 84: 1186-1190.

Korb, J.-P., McDonald, P.J., Monteilhet, L., Kalinichev, A.G., Kirkpatrick, R.J. (2007) Comparison of proton fieldcycling relaxometry and molecular dynamics simulations for proton-water surface dynamics in cement-based materials. Cement and Concrete Research, 37: 348-350.

Kumar, P., Kalinichev, A.G., Kirkpatrick, R.J. (2007a) Dissociation of carbonic acid: Gas phase energetics and mechanism from ab initio metadynamics simulations. Journal of Chemical Physics 126: 204315-1-7. 
Kumar, P., Kalinichev, A.G., Kirkpatrick, R.J. (2007b) Molecular dynamics simulation of the energetics and structure of layered double hydroxides intercalated with carboxylic acids. Journal of Physical Chemistry C 111: 13517 - 13523.

Kumar, P., Kalinichev, A.G., Kirkpatrick, R.J. (2008) Hydrogen bonding structure and dynamics of aqueous carbonate species from Car-Parrinello molecular dynamics simulations. J.Phys.Chem.B, (accepted for publication).

Larsen, F. H., Jakobsen, H.J., Ellis, P.D., Nielsen, N.C. (1997) Sensitivity-enhanced quadrupolar-echo NMR of half-integer quadrupolar nuclei. Magnitudes and relative orientation of chemical shielding and quadrupolar coupling tensors. Journal of Physical Chemistry A 101(46): 8597-8606.

Li, Q. and Kirkpatrick, R.J. (2007) Organic anions in layered double hydroxides: An experimental investigation of citrate hydrotalcite American Mineralogist 92: 397-402.

Mason, J. E. (1987) Multinuclear NMR. New York, Plenum Press.

Osman, M.A., and Suter, U.W. (2000) Determination of the cation-exchange capacity of muscovite mica. Journal of Colloid and Interfacial Science 224: 112-115.

Ostroverkhov, V., Waychunas, G.A., Shen, Y.R. (2004) Vibrational spectra of water at water / $\alpha$-quartz (0001) interface. Chemical Physics Letters 386: 144-148.

Ostroverkhov, V., Waychunas, G.A., Shen, Y.R. (2005) New information onwater interfacial structure revealed by phase-sensitive surface spectroscopy. Physical Review Letters 94: 046102-1-4.

Sanz, J., Herrero, C.P., Serratosa, J.M. (2006) Arrangement and mobility of water in vermiculite hydrates followed by 1H NMR spectroscopy. Journal of Physical Chemistry B 110: 7813-7819.

Sutton, R., Sposito, G., Diallo, M. S., and Schulten H.R. (2005) Molecular simulation of dissolved organic matter. Environmental Toxicology and Chemistry, 24, 1902-1911.

Ufimtsev, I.S., Kalinichev, A.G., Martinez, T.J., Kirkpatrick, R.J. (2007) A charged ring model for classical OH(aq) simulations. Chemical Physics Letters 442: 128-133.

Ufimtsev, I.S., Kalinichev, A.G., Martinez, T.J., Kirkpatrick, R.J. (2008) A multistate empirical valence bond model for molecular simulations of the hydroxide ion solvation and transport in aqueous solutions, Journal of Chemical Physics, (in review).

Wang, J. W., Kalinichev, A.G., Kirkpatrick, R.J. (2003) Molecular dynamics modeling of confined water. Abstracts of Papers of the American Chemical Society 226: U601-U601.

Wang, J. W., Kalinichev, A.G., Kirkpatrick, R.J. (2004) Molecular modeling of water structure in nano-pores between brucite (001) surfaces. Geochimica et Cosmochimica Acta 68(16): 3351-3365.

Wang, J. W., Kalinichev, A.G., Kirkpatrick, R.J., Cygan, R.T. (2005) Structure, energetics, and dynamics of water adsorbed on the muscovite (001) surface: A molecular dynamics simulation. Journal of Physical Chemistry B 109(33): 15893-15905.

Wang, J. W., Kalinichev, A.G., Kirkpatrick, R.J. (2006) Effects of substrate structure and composition on the structure, dynamics, and energetics of water at mineral surfaces: A molecular dynamics modeling study. Geochimica et Cosmochimica Acta 70(3): 562-582.

Wang, J. W., Kalinichev, A.G., Kirkpatrick, R.J., Hou, X.Q. (2001) Molecular modeling of the structure and energetics of hydrotalcite hydration. Chemistry of Materials 13(1): 145-150.

$\mathrm{Xu}, \mathrm{X}$. and Kirkpatrick, R.J. (2006) $\mathrm{NaCl}$ interaction with interfacially polymerized polyamide films of reverse osmosis membranes: A solid-state Na-23 NMR study. Journal of Membrane Science 280(1-2): 226-233.

$\mathrm{Xu}$, X., Kalinichev, A. G., and Kirkpatrick, R. J. (2006) ${ }^{133} \mathrm{Cs}$ and ${ }^{35} \mathrm{Cl}$ NMR spectroscopy and molecular dynamics modeling of $\mathrm{Cs}^{+}$and $\mathrm{Cl}^{-}$complexation with natural organic matter. Geochimica et Cosmochimica Acta, 70, 4319-4331.

Yu, P. and Kirkpatrick, R.J. (2001) Cl-35 NMR relaxation study of cement hydrate suspensions. Cement and Concrete Research 31(10): 1479-1485. 